\title{
Independent Current Control of Dual Parallel SRM Drive Using a Public Current Sensor
}

\author{
Chun Gan, Member, IEEE, Jianhua Wu, Ning Wang, Yihua Hu, Senior Member, IEEE, \\ Wenping Cao, Senior Member, IEEE, and Shiyou Yang
}

\begin{abstract}
Switched reluctance motors (SRMs) have been considered as a potential candidate for automotive applications due to its rare-earth-free feature and wide speed range. Conventionally, a current sensor is installed in each phase for the current regulation control, which will considerably add the cost and volume to multi-motor drives. This paper proposes an independent current control technique for dual parallel SRM drives using only one current sensor. In order to identify the individual motor currents from the public current, a pulse injection scheme is developed accordingly. Two pulses are individually injected into the lower-transistors of the dual converter in the excitation regions; and the fixed current sampling points triggered by the injected pulse are presented for motor current identification. The independent current control for the dual SRM can be directly implemented by the public current sensing although the motor parameters are different. The developed system requires only one current sensor without additional hardware or reduced system performance. The simulation and experimental results on parallel $750 \mathrm{~W}$ and 150 W three-phase 12/8 SRM drives are presented to confirm the effectiveness of the proposed method. With this scheme, the dual motor drive can be more compact and cost-effective for traction drive applications.
\end{abstract}

Index Terms-Dual motor drive, independent current control, public current sensor, current sampling, pulse injection, switched reluctance motors (SRMs).

\section{INTRODUCTION}

Electric vehicles (EVs) and hybrid electric vehicles (HEVs) have received significant interest in recent years, due to economic and environmental concerns linked to the rapid depletion of the fossil fuels and exhaust gas emissions [1], [2]. In terms of electric motor drive technology, permanent-magnet synchronous machines (PMSMs) are proved to be a popular option due to their high efficiency and high torque density [3][5]. However, the permanent magnets essential to the PMSM are fabricated from rare-earth materials which bring about environmental issues, high cost and poor heat stability. Therefore, much effort has been shifted to developing rareearth-free or rare-earth-less motors for future traction drives [6], [7]. Switched reluctance motors (SRMs) have a simple and rugged structure without any rotor windings or permanent magnets. They are characterized with low cost, high efficiency, and high reliability especially suited for operation in harsh vehicular environments [8]-[17].

Dual-motor drives are a promising topology for traction drives [18], [19]. As shown in Fig. 1, two motors and two converters are used to boost the output torque and power. In case a converter or motor is failed, the system can still operate with the remaining motor and converter, so that a fault tolerated operation is achieved. The dual motor drive can be used for safety-critical applications, such as the electric propulsion for vehicles, electric aircrafts and ships. Fig. 2 shows a dual parallel SRM drive system [20]. The system consists of two SRMs, two converters, two drive circuits, but one controller and one power supply.

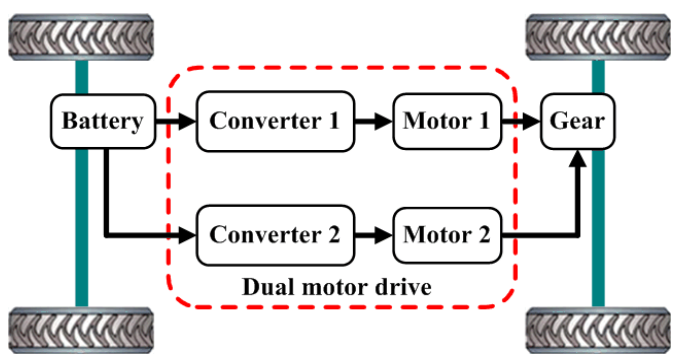

Fig. 1. Dual motor drive in the EV/HEV [18].

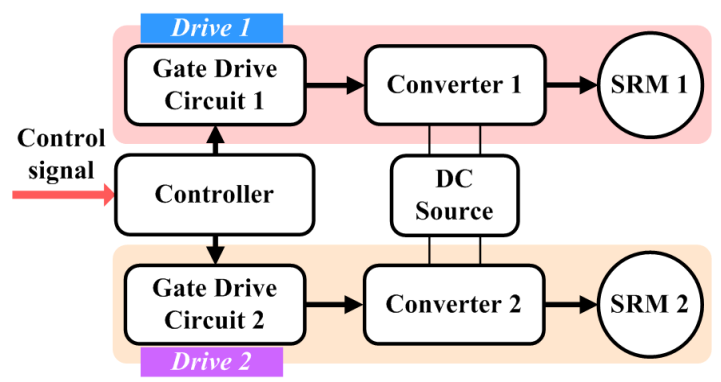

Fig. 2. Dual SRM drive system [20].

Multi-drive technologies have been widely employed in safety-critical and high-performance applications. A multimotor vector controlled drive system fed by a single voltage source is developed in [21], and a parallel-connected multiphase multi-drive system is designed in [22]. A dualchannel 12/8 SRM divided into two equivalent 6/4 motors and driven by two sets of power converters can lead to a highreliable motor drive. Performance of the dual-channel SRM under single- and dual-channel operational modes is investigated and compared in [23], and a dynamic modeling strategy considering mutual coupling is proposed and detailed in [24]. A new cascade dual buck inverter with a phase-shift control scheme is proposed in [25], which eliminates the inherent current zero-crossing distortion to improve reliability. In [26], a micro control unit with control law accelerator architecture is proposed, which integrates the dual-motor 
control and power factor correction functions in a single controller for heating ventilation and air conditioning drives. Independent current control schemes for a dual three-phase induction motor (IM) drive fed by a five-leg inverter is considered in [27], [28], by using an existing pulse width modulation (PWM) technique in conjunction with fieldoriented control.

In a current-controlled motor drive, the phase currents are needed for feedback control [29]-[31]. Generally, these phase current sensors give rise to the cost and volume of the motor drive. As a result, a three-phase dual motor drive system would need six sensors as compared to three in a single motor drive system. To reduce the current sensors, cost-effective current sampling schemes have attracted great attention [32]-[41]. In order to achieve a low-cost dual SRM drive using the least sensors and satisfy the application requirements, the system should require the following conditions: 1) accurate current sensing; 2) independent current control of the two motors although the motor and control parameters are different; 3) little change to the traditional SRM drive topology; 4) relative low cost without added circuits; 5) little distortion to the currents.

This paper proposes an independent current control technique for a dual SRM drive using only a public current sensor to match the above conditions. Two parallel three-phase 12/8 SRM drives are employed to analyze the phase current. A low-cost public current sensor placing strategy in the parallel converters is presented. In order to identify each motor current from the public current, two phase-shifted pulses are injected into the lower-transistors of the dual converter to insert the detection states. Two analog to digital (A/D) conversion channels are triggered in the low-level of the two pulses, respectively, to sample the public current. Experiments are carried out on the $750 \mathrm{~W}$ and $150 \mathrm{~W} 12 / 8$ dual SRM drive to validate the proposed scheme. The dynamic performance of the dual motor drive with two independent closed-loop controllers is presented. Performance comparisons between the traditional and proposed methods are also investigated in details. With this scheme, the two motors can be controlled independently by using only a public current sensor, although the control parameters for each motor are different. The proposed scheme also provides a simple and reliable faulttolerance method for current sensor faults in high performance and safety critical applications.

\section{Proposed CuRRent SAMPling TECHNIQUE}

\section{A. Dual SRM Drive}

Fig. 3 shows a dual parallel three-phase SRM drive powered by a dc source. An asymmetric converter is employed in the system due to its phase isolation. Each phase leg is controlled independently by two switches and is independent of one another, providing good controllability and fault-tolerance capability. Even though one converter is failed, another one can still operate in a single-motor mode with compromised performance. The phase currents are essential for the current regulation control, and a current sensor is needed for each phase.

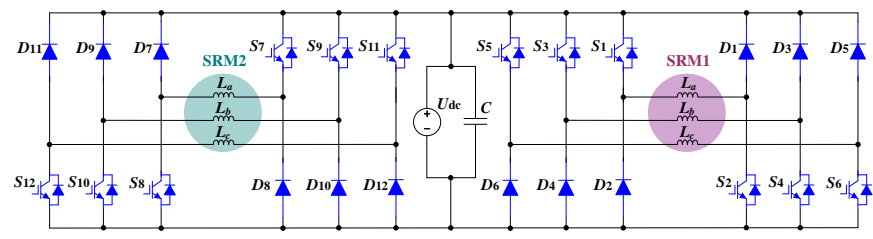

Fig. 3. Three-phase dual SRM drive powered by a dc source.

When transistors $S_{1}$ and $S_{2}$ are both on, phase A is energized by the dc source, and it works in the excitation mode. When $S_{1}$ is off and $S_{2}$ is on, the phase A current flows in the freewheeling mode through $S_{2}$ and diode $D_{2}$. When $S_{1}$ and $S_{2}$ both shut off in the phase turn-off region, the phase A current feed back to the dc source through $D_{1}$ and $D_{2}$ in the demagnetization mode. As illustrated in Fig. 4, in the excitation region, a current command $i_{r e f}$, is enforced with a current feedback loop where it is compared with the instantaneous phase current $i_{a}$. The current amplitude limits are presumed to be processed though a hysteresis controller with a current hysteresis width of $\triangle i$. If the instantaneous current exceeds the maximum value $i_{\text {max }}, S_{1}$ is turned off and $S_{2}$ remains on, and the phase current will decrease rapidly, bringing it below the minimum value $i_{\text {min }}$, then $S_{1}$ is turned on to increase the phase current.

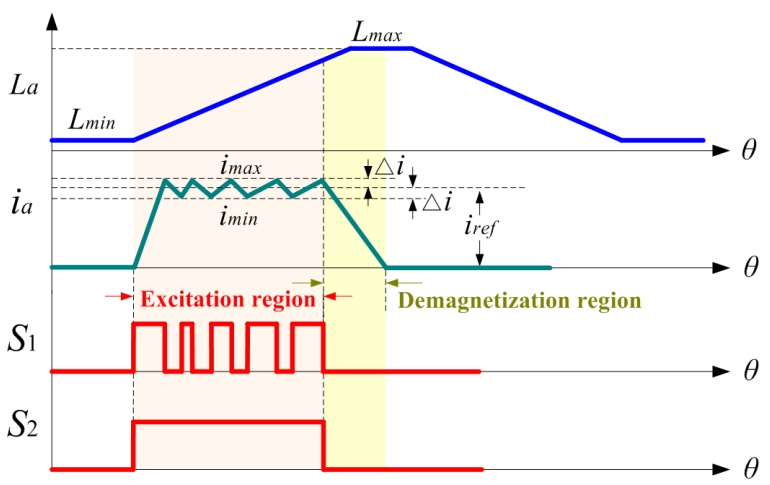

Fig . 4. Phase current waveform under current hysteresis control.

\section{B. Phase Current in the Dual SRM Drive}

The phase currents and switching states of the dual motor in a conduction cycle are shown in Fig. 5 . In the figure, $i_{a}, i_{b}$, and $i_{c}$ are the phase $\mathrm{A}$, phase $\mathrm{B}$, and phase $\mathrm{C}$ currents for motor 1 , respectively; $i_{d}, i_{e}$ and $i_{f}$ are the phase $\mathrm{D}$, phase $\mathrm{E}$ and phase $\mathrm{F}$ currents for motor2, respectively; $S_{1}, S_{3}, S_{5}, S_{7}, S_{9}$ and $S_{11}$ are the drive signals for the upper-transistors, respectively; and $S_{2}$, $S_{4}, S_{6}, S_{8}, S_{10}$ and $S_{12}$ are the drive signals for the lowertransistors, respectively. $\theta_{1}$ is the turn-on angle of phases $\mathrm{B} ; \theta_{2}$ is the turn-off angle of phases $\mathrm{B} ; \theta_{3}$ is the turn-on angle of phases $\mathrm{C}$; and $\theta_{4}$ is the current ending angle of phases $\mathrm{B}$. If there are no overlapped regions between the drive signals of adjacent phases in a single motor (see Fig. 5), the dc current contains one excitation current and one demagnetization current in a single motor at most at each rotor position. 


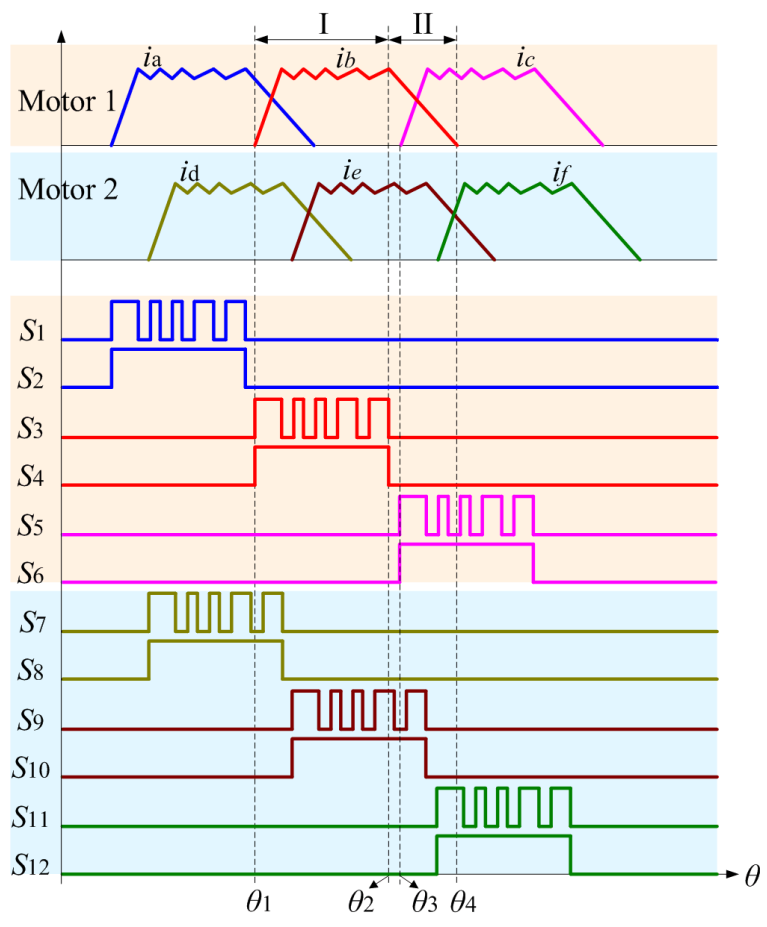

Fig. 5. Phase currents and switching states.

The angle difference between the turn-on angles of the adjacent phases is equal to a stroke angle, given by

$$
\theta_{\text {diff }}=\frac{360^{\circ}}{m \times N_{r}}
$$

where $m$ is the number of phases, $N_{\mathrm{r}}$ is the number of rotor poles. For a three-phase 12/8 SRM, $m=3$ and $N_{\mathrm{r}}=8$. Therefore, $\theta_{\text {diff }}=15^{\circ}$.

$\theta_{3}$ and $\theta_{1}$ satisfy

$$
\theta_{3}=\theta_{1}+\theta_{\text {diff }}=\theta_{1}+15^{\circ}
$$

In Fig. 5, Region I and Region II are the excitation region and demagnetization region of phase $\mathrm{B}$, respectively. If the phase $\mathrm{B}$ and phase $\mathrm{C}$ currents in the excitation region (i.e., excitation current) have non-overlapped regions, $\theta_{2}$ and $\theta_{1}$ should satisfy

$$
\theta_{2} \leq \theta_{1}+15^{\circ}
$$

In Region I, the demagnetization currents of phases A and D and the excitation currents of phases B, D and E are all contained in the public dc current. However, only the excitation current is needed to implement current control algorithm. If the demagnetization currents of phases A and D are both removed from this region, only the excitation currents of phases B, D and E will be contained in the public dc current, and only two excitation currents are overlapped at most at each rotor position. Likewise, in Region II, if the demagnetization currents of phases $\mathrm{B}$ and $\mathrm{E}$ are removed, only the excitation currents of phases $\mathrm{C}, \mathrm{E}$ and $\mathrm{F}$ will be contained in the public dc current, and there are also only two excitation currents overlapped at most at each rotor position.

\section{Proposed Current Sampling Scheme for Dual SRM} Drive

The conventional current sensor placing strategy is to install a current sensor in each phase and use individual A/D conversion channels to identify these currents. Without a doubt, the phase current sensors add the cost, volume and complexity to the dual drive system. In this paper, a low-cost public current sensor placing strategy is proposed to remove the phase current sensors, as shown in Fig. 6. All the anodes of the lower-diodes are connected together to the dc power supply, and all the emitters of the lower-transistors are also connected together though a public current sensor to the dc power supply. In this converter, there are only excitation currents across the public current sensor, without the demagnetization current of each phase contained in the public current.

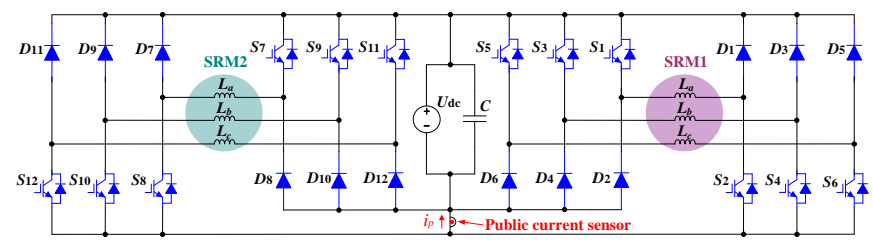

Fig. 6. Public current sensor placing strategy in the parallel converters.

The switching functions of the power switches in the dual motor drive are defined as

$$
S_{1 \sim 12}= \begin{cases}1, & \text { Lower-transistor is on } \\ 0, & \text { Lower-transistor is off }\end{cases}
$$

According to the phase currents and switching functions, the public current can be expressed as

$$
i_{p}=i_{a} S_{2}+i_{b} S_{4}+i_{c} S_{6}+i_{d} S_{8}+i_{e} S_{10}+i_{f} S_{12}
$$

If the transistors $S_{2}, S_{4}$ and $S_{6}$ are shut off during a series of short times in the excitation regions of motor 1 , and the transistors $S_{8}, S_{10}$ and $S_{12}$ remain their original states during these times, the public current only contains the excitation currents of motor 2 in these inserted times. Owing to no overlapped regions between the drive signals of the lowertransistors in a single motor, the detected public current at these times is directly the phase current of motor2 in each excitation region. Similarly, if the transistors $S_{8}, S_{10}$ and $S_{12}$ are shut off during another series of short times in the excitation regions of motor2, and the transistors $S_{2}, S_{4}$ and $S_{6}$ remain their original states during these times, the public current only contains the excitation currents of motor 1 at these inserted times. Likewise, if the public current is sampled at these times, the detected current is directly the phase current of motor1 in each excitation region.

Fig. 7 illustrates the pulses injection mode and sampling instants of the public current for the dual motor drive. The two injected pulses have the same frequency and duty cycle, and some phase shift between each other. Pulse1 is injected into the lower-transistors of phases $\mathrm{A} \sim \mathrm{C}$ in their excitation regions, and A/D1 is triggered in the low-level of pulse 1 to sample the public current for phase $\mathrm{D} \sim \mathrm{F}$ currents identification, 
respectively. Similarly, pulse2, shifted by a half period to pulse 1, is injected into the lower-transistors of phases D F in their excitation regions, and A/D2 is triggered in the low-level of pulse 2 to sample the public current for phase $A \sim B$ currents identification, respectively.

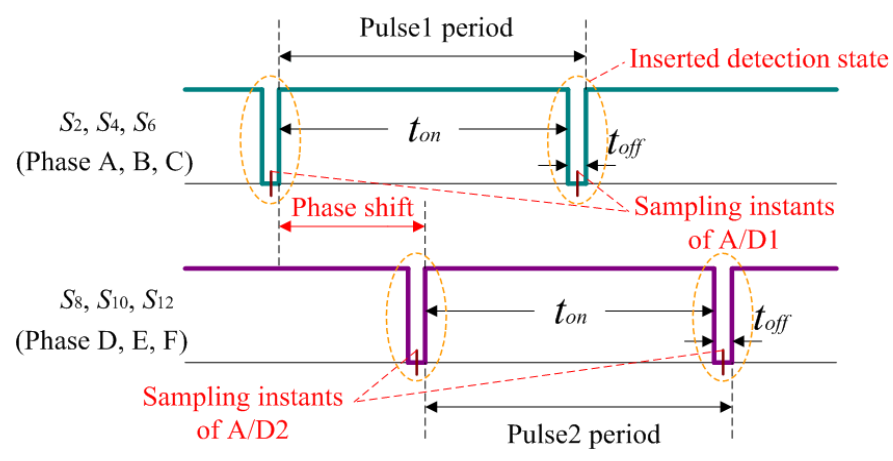

Fig. 7. Pulses injection method and sampling instants.

From the analysis above, the phase currents of motor 1 and motor 2 in their excitation regions can be completely obtained according to the switching states and sampled public current under dual pulse injection, given by

$$
\begin{aligned}
& \left\{\begin{array}{l}
i_{a}{ }^{\prime}=i_{p 2} \cdot S_{2} \\
i_{b}{ }^{\prime}=i_{p 2} \cdot S_{4} \\
i_{c}{ }^{\prime}=i_{p 2} \cdot S_{6}
\end{array}\right. \\
& \left\{\begin{array}{l}
i_{d}{ }^{\prime}=i_{p 1} \cdot S_{8} \\
i_{e}{ }^{\prime}=i_{p 1} \cdot S_{10} \\
i_{f}{ }^{\prime}=i_{p 1} \cdot S_{12}
\end{array}\right.
\end{aligned}
$$

where $S_{2} \sim S_{12}$ are the conventional drive signals prior to the two pulses injection; $i_{p 1}$ and $i_{p 2}$ are the sampled public current by $\mathrm{A} / \mathrm{D} 1$ and $\mathrm{A} / \mathrm{D} 2$ with pulse1 and pulse 2 injections in the low-level of the pulses, respectively; $i_{a}{ }^{\prime} \sim i_{f}{ }^{\prime}$ are the identified phase currents from the sampled public current.

Therefore, the current control scheme for the dual motor drive can be directly implemented by the identified currents from the public current. The inserted detection states, i.e., the turn-off times of the pulse, should be extremely short, because these detection states possibly lead to current distortion. In order to minimize the influence on the current, the frequency and duty cycle of the inserted pulses should be set both large enough for an extremely short turn-off time. However, if the duty cycle is much close to 1 , the phase current may not be reliably detected because the available acquisition times are too short. To ensure the current sensors and analog to digital (A/D) converters have enough time to sample the current, a minimum measurement time should be determined by

$$
T_{\min }=\max \left(T_{s r}, T_{a d}\right)
$$

where $T_{s r}$ is the response time of the current sensor and $T_{a d}$ is the acquisition time of the A/D converter.

The switching frequency $f$ and duty cycle $D$ of the inserted pulse should satisfy

$$
T_{\text {off }}=\frac{1-D}{f} \geq T_{\min }
$$

\section{Current Distortion under Pulse Injection}

The voltage and current equations of phase $\mathrm{A}$ are given by

$$
\begin{aligned}
U_{a} & =R_{a} i_{a}+L_{a}\left(i_{a}, \theta_{r}\right) \frac{d i_{a}}{d t}+i_{a} \omega_{r} \frac{d L_{a}\left(i_{a}, \theta_{r}\right)}{d \theta_{r}} \\
& =L_{a}\left(i_{a}, \theta_{r}\right) \frac{d i_{a}}{d t}+i_{a}\left[R_{a}+\omega_{r} \frac{d L_{a}\left(i_{a}, \theta_{r}\right)}{d \theta_{r}}\right] \\
i_{a}(t) & =I_{a 0} \exp \left(-\frac{t}{\tau_{a}}\right)+\frac{U_{a}}{R_{e q_{-} a}}\left[1-\exp \left(-\frac{t}{\tau_{a}}\right)\right]
\end{aligned}
$$

where $R_{\text {eq_a }}$ and $\tau_{a}$ denote as

$$
\begin{gathered}
R_{e q_{-} a}=R_{a}+\omega_{r} \frac{d L_{a}\left(i_{a}, \theta_{r}\right)}{d \theta_{r}} \\
\tau_{a}=\frac{L_{a}\left(i_{a}, \theta_{r}\right)}{R_{\mathrm{e}_{-} a}}
\end{gathered}
$$

where $U_{a}$ is the phase A voltage, $i_{a}$ is the phase A current, $\theta_{r}$ is the rotor angular position, $L_{a}\left(\theta_{r}, i_{a}\right)$ is phase A inductance depending on the rotor position and phase current, $I_{a 0}$ is the initial phase A current, $R_{a}$ is the phase A resistance, and $\omega_{r}$ is the motor angular speed.

Fig. 8 shows the electrical level under pulse injection for excitation current identification. When the two motors are operated independently at different speeds, phase A current may overlap with any phase current of motor2 (i.e., $i_{x} ; x=d, e$ and $f$ ). In the phase A current ascending region, if the up-level of the pulse is injected into phase A, the upper-transistor and lower-transistor are both on, and the phase A voltage remains the positive dc-link voltage $U_{d c}$; if the low-level of the pulse is injected into phase $\mathrm{A}$, the upper-transistor remains on and the lower-transistor turns off, and the phase A voltage changes from $U_{d c}$ to zero. Similarly, in the current descending region of phase A, if the up-level of the pulse is injected into phase A, the upper-transistor is off and lower-transistor is on, and the phase A voltage remains zero; if the low-level of the pulse is injected into phase $\mathrm{A}$, the upper-transistor and the lowertransistor are both turned off, and the phase A voltage changes from zero to the negative dc-link voltage $-U_{d c}$.

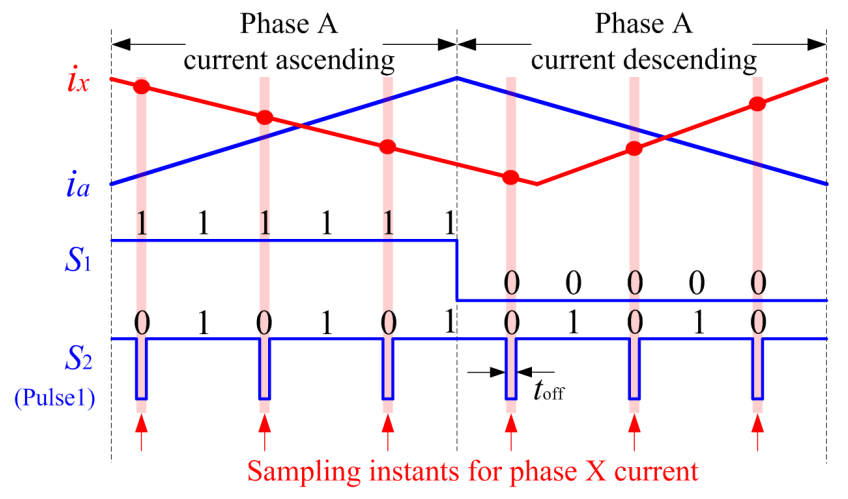

Fig. 8. Electrical level under pulses injection in a current chopping period. 
Thus, phase A voltage is determined by the different switching states under pulse injection as follow

$$
U_{a}= \begin{cases}U_{d c}, & S_{1}=1, S_{2}=1 \\ 0, & S_{1}=1, S_{2}=0 \\ 0, & S_{1}=0, S_{2}=1 \\ -U_{d c}, & S_{1}=0, S_{2}=0\end{cases}
$$

Fig. 9 shows the current distortion, i.e., $\triangle i_{a_{-} \text {up }}$ and $\triangle i_{a_{-} \text {down }}$, caused by the pulse injection. In the figure, $i_{a_{-} \text {up }}$ and $i_{a_{-} \text {up }}$ are the phase A current before and after pulse injection in the current ascending region at the time $t_{\text {off }}$, respectively; $i_{a_{-} \text {down }}$ and $i_{a_{-} \text {down' }}$ are the phase A current before and after pulse injection in the current descending region at the time $t_{\text {off }}$, respectively.

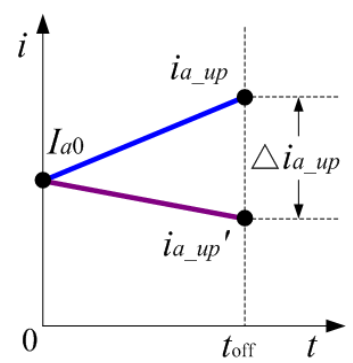

(a)

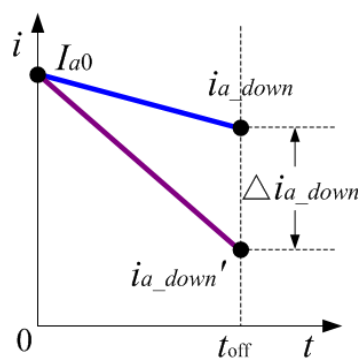

(b)
Fig. 9. Current distortion under pulse injection. (a) In the current ascending region. (a) In the current descending region.

The phase A current before and after the pulse injection in phase A current ascending region at the time $t_{\text {off }}$ are expressed as (15) according to (11) and (14).

$$
\left\{\begin{array}{l}
i_{a_{-} u p}\left(t_{o f f}\right)=I_{a 0} \exp \left(-\frac{t_{\text {off }}}{\tau_{a}}\right)+\frac{U_{d c}}{R_{e q_{-} a}}\left[1-\exp \left(-\frac{t_{o f f}}{\tau_{a}}\right)\right] \\
i_{a_{-} u p}{ }^{\prime}\left(t_{\text {off }}\right)=I_{a 0} \exp \left(-\frac{t_{\text {off }}}{\tau_{a}}\right)
\end{array}\right.
$$

Likewise, the phase A current before and after the pulse injection in phase A current descending region at the time $t_{\text {off }}$ are expressed as (16) according to (11) and (14).

$$
\left\{\begin{array}{l}
i_{a_{-} \text {down }}\left(t_{\text {off }}\right)=I_{a 0} \exp \left(-\frac{t_{\text {off }}}{\tau_{a}}\right) \\
i_{a_{-} \text {down }}{ }^{\prime}\left(t_{\text {off }}\right)=I_{a 0} \exp \left(-\frac{t_{\text {off }}}{\tau_{a}}\right)-\frac{U_{d c}}{R_{\text {eq_a }}}\left[1-\exp \left(-\frac{t_{\text {off }}}{\tau_{a}}\right)\right]
\end{array}\right.
$$

The phase A current distortion in the current ascending and descending regions with pulse injection into the lowertransistor are expressed as (17) and (18), respectively, according to (15) and (16).

$$
\begin{gathered}
\Delta i_{a_{-} u p}\left(t_{o f f}\right)=i_{a_{-} u p}\left(t_{o f f}\right)-i_{a_{-} u p}{ }^{\prime}\left(t_{o f f}\right)=\frac{U_{d c}}{R_{e q_{-} a}}\left[1-\exp \left(-\frac{t_{\text {off }}}{\tau_{a}}\right)\right] \\
\Delta i_{a_{-} \text {down }}\left(t_{\text {off }}\right)=i_{a_{-} \text {down }}\left(t_{\text {off }}\right)-i_{a_{-} \text {down }}{ }^{\prime}\left(t_{\text {off }}\right)=\frac{U_{d c}}{R_{\text {eq_a }}}\left[1-\exp \left(-\frac{t_{\text {off }}}{\tau_{a}}\right)\right]
\end{gathered}
$$

Since pulse 1 and pulse 2 both have high frequency and large duty cycle, the turn-off time in a pulse period is extremely short, which has little impact on the phase current, given by

$$
\lim _{t_{\text {off }} \rightarrow 0} \Delta i_{a_{-} u p}\left(t_{\text {off }}\right)=\lim _{t_{\text {off }} \rightarrow 0} \Delta i_{a_{-} \text {down }}\left(t_{\text {off }}\right)=0
$$

\section{E. Popularization and Application}

Due to the independent current sensing for the two motors, the proposed public-sensor based technique can provide independent control for any dual parallel motor drives although the two motors have different phases, as shown in Fig. 10. Likewise, pulse 1 is injected into the lower-transistors of M-phase SRM converter in the excitation regions to detect the current of N-phase SRM; phase-shifted pulse 2 is injected into the lower-transistors of N-phase SRM converter in the excitation regions to detect the current of M-phase SRM. The detected currents by two A/D convention channels triggered in the low-level of the injected pulses can be directly used for independent control of the two motors.

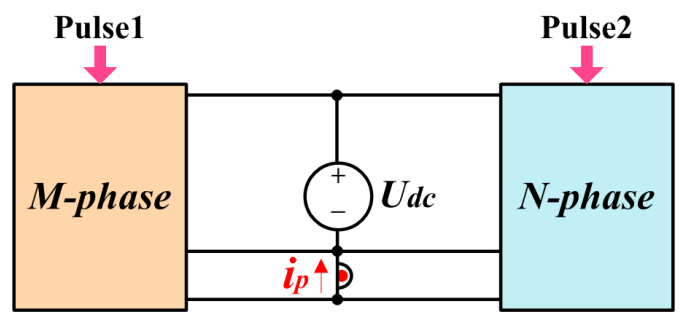

Fig.10. M-phase and N-phase SRMs operated by using only a public current sensor.

\section{EXPERIMENTAL VERIFICATION}

In order to verify the proposed scheme, a $750 \mathrm{~W}$ and a 150 W three-phase 12/8 SRM are employed to build an experimental test-rig. Its photo and schematic diagram are illustrated in Fig. 11. The main system parameters are summarized in Table I. In the experiments, the two SRMs are powered by a dc source and driven by two sets of asymmetric converters connected in parallel. The used IGBTs are IKW75N60T and diodes are IDW75E60, both from Infineon Technologies. The rotor positions of the two motors are obtained by using the incremental encoders. A dSPACE-1006 platform is employed as the main controller to implement the proposed control scheme. A Hall-effect current sensor (LA$55 \mathrm{P})$ is installed in the drive to measure the public current which is simultaneously sampled by two 14-bit A/D conversion channels though the operational amplifiers. For comparison purposes, six additional LA-55Ps are also installed in each phase to measure the actual phase currents. The experimental waveforms are observed in a multi-channel oscilloscope. As illustrated in Fig. 11(b), two pulses are injected into the lower-transistors of the dual motor drive to generate the new drive signals for converter 1 and converter 2 , respectively. The frequency, duty cycle and phase-shift time of the injected pulses are set to $20 \mathrm{kHz}, 95 \%$, and $25 \mu \mathrm{s}$, respectively. Two dependent current hysteresis controllers are designed to regulate the currents for the two motors. 


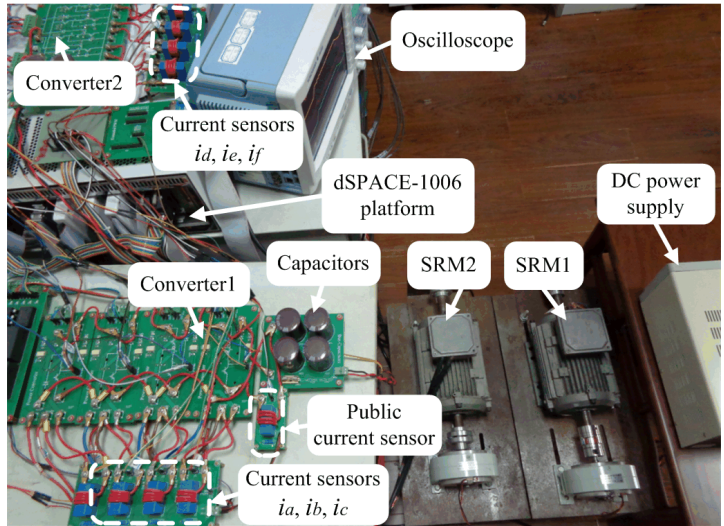

(a)

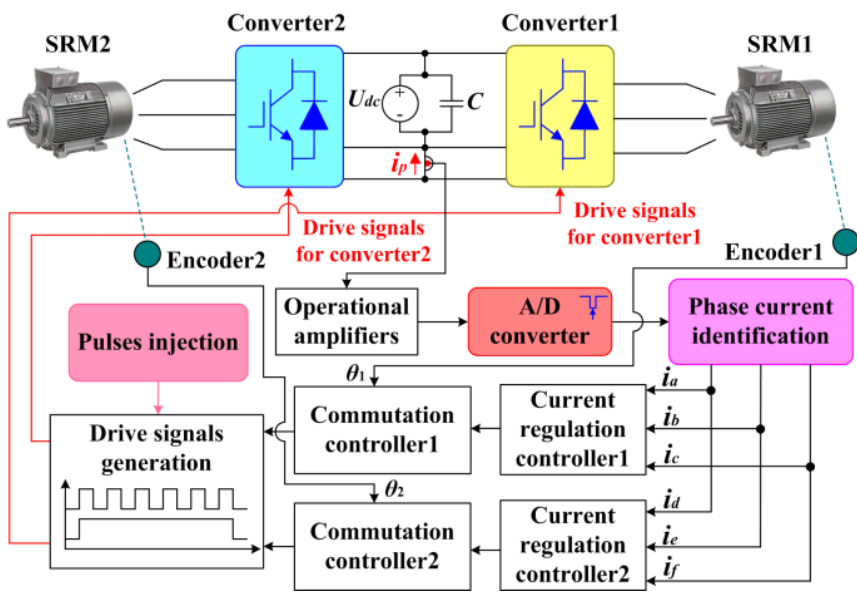

(b)

Fig. 11. Experimental system. (a) Photo of the experimental setup. (b) Schematic diagram.

TABLE I

SYSTEM PARAMETERS

\begin{tabular}{lcc}
\hline \hline Parameter & $\begin{array}{c}\text { Value for the } \\
\text { SRM1 }\end{array}$ & $\begin{array}{c}\text { Value for the } \\
\text { SRM2 }\end{array}$ \\
\hline Phase number & 3 & 3 \\
Stator/rotor poles & $12 / 8$ & $12 / 8$ \\
Rated power (W) & 750 & 150 \\
Rated speed (r/min) & 1500 & 1500 \\
Rotor outer diameter (mm) & 55 & 54 \\
Rotor inner diameter (mm) & 30 & 25 \\
Stator outer diameter (mm) & 102.5 & 102 \\
Stator inner diameter (mm) & 55.5 & 54.5 \\
Stack length (mm) & 80 & 58 \\
Stator arc angle (deg) & 14 & 15 \\
Rotor arc angle (deg) & 16 & 18 \\
Current hysteresis width (A) & 0.1 & 0.1 \\
Encoder lines & 2500 & 2500 \\
Proportional gain & 0.05 & 0.02 \\
Integral gain & 0.02 & 0.01 \\
\hline \hline
\end{tabular}

Fig. 12 shows the public current, phase currents and drive signals of the lower-transistors prior to pulse injection. Motor1 and motor 2 are operated at 300 and $400 \mathrm{r} / \mathrm{min}$, respectively, with different rotor initial positions. The turn-on and turn-off angles of the two motors are both set to $0^{\circ}$ and $15^{\circ}$, respectively. The excitation currents are not overlapped between each phase in a single motor. In order to separate the overlapped phase currents between the two motors, the pulse injection scheme is employed for public current sampling.
Fig. 13 shows the public current, phase currents and drive signals of the lower-transistors under pulses injection, when motor 1 and motor 2 are operated at 300 and $400 \mathrm{r} / \mathrm{min}$, respectively. As shown in Fig. 13(a), in order to detect the excitation currents of motor2, pulse 1 is injected into all the lower-transistors of motor 1 in the excitation regions. Clearly, the lower profile of the public current is directly the excitation current of each phase in motor2. Therefore, A/D1 is triggered in the low-level of pulse 1 to sample the public current for motor 2 current identification. Similarly, in order to detect the excitation currents of motor1, pulse 2 is injected into all the lower-transistors of motor2 in the excitation regions, as shown in Fig. 13(b). Clearly, the lower profile of the public current is directly the excitation current of each phase in motor1. In this state, A/D2 is triggered in the low-level of pulse2 to sample the public current for motor 1 current identification. Fig. 13(c) shows the individual current detection for the two motors in their overlapped region with two phase-shifted pulses (pulse1 and pulse2) injected simultaneously. Pulse1 is injected into the lower-transistor of phase A for phase D current detection; simultaneously, pulse 2 is injected into the lower-transistor of phase $\mathrm{D}$ for phase A current detection. The lower profile of the public current is separated into two parts, where one matches well with phase A current, and another one matches well with phases D current. A/D1 and A/D2 are triggered in the lowlevel of the two pulses, respectively, to sample each current.

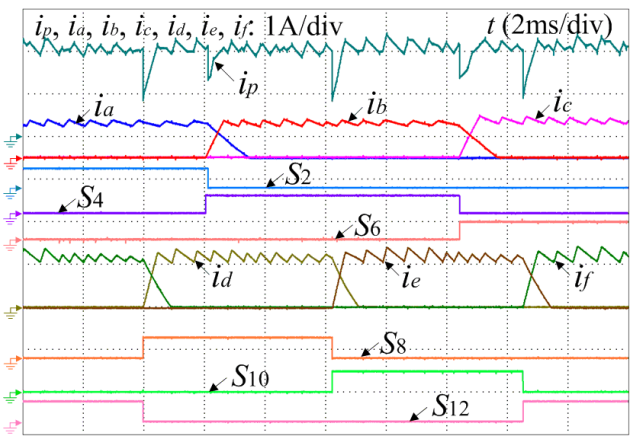

Fig. 12. Public current, phase currents and drive signals prior to pulse injection.

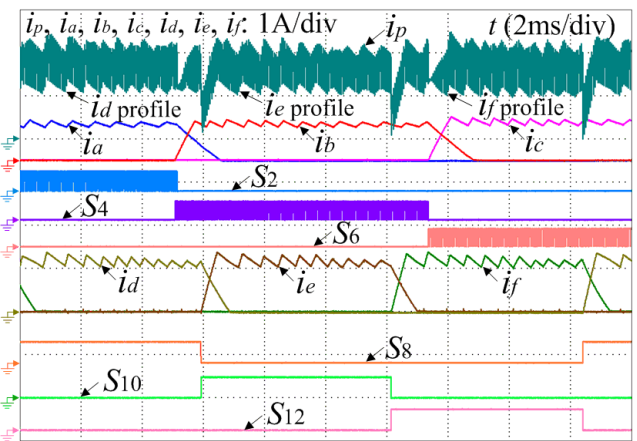

(a) 


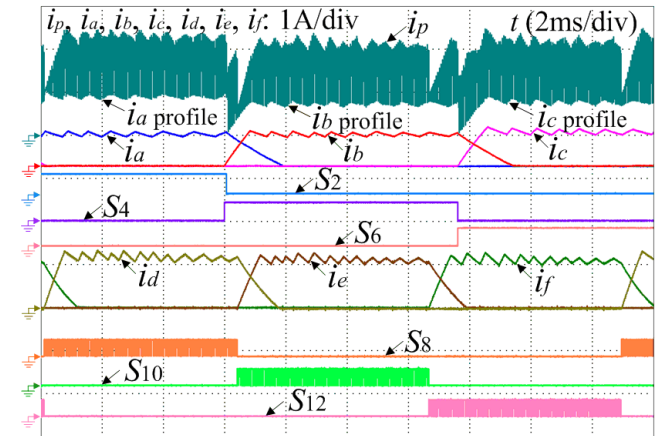

(b)

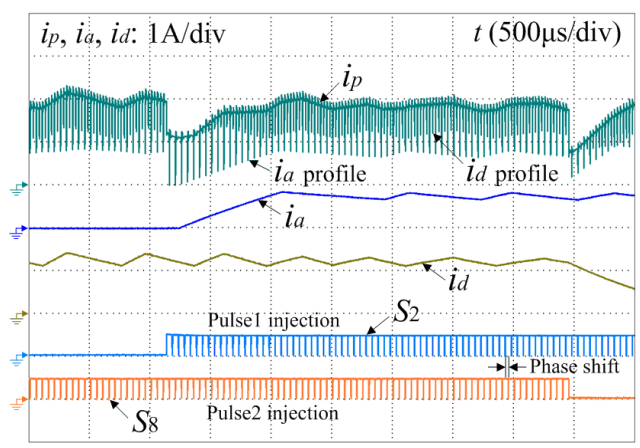

(c)

Fig. 13. Motor current detection under pulse injection. (a) Current detection for motor1. (b) Current detection for motor2. (c) Individual current detection for the two motors in their overlapped region with phase-shifted pulses.

In order to observe the current distortion, the identified excitation currents from the public current are observed through a multi-channel D/A converter and compared with the actual sampled phase currents in Fig. 14, where $i_{a}$ and $i_{d}$ are the actual currents sampled by the phase current sensor, $i_{a}{ }^{\prime}$ and $i_{d}$ are the identified currents sampled by the public current sensor, and $e_{a}$ and $e_{b}$ are the absolute errors between the actual and identified phase currents. From the comparisons, it can be seen that when motor 1 and motor 2 are operated at 300 and $400 \mathrm{r} / \mathrm{min}$, respectively, the maximum current errors are 0.02 $\mathrm{A}$ in phase $\mathrm{A}$ and $0.018 \mathrm{~A}$ in phase $\mathrm{D}$; when motor1 and motor 2 are operated at 1200 and $1500 \mathrm{r} / \mathrm{min}$, respectively, the maximum current errors are $0.016 \mathrm{~A}$ in phase $\mathrm{A}$ and $0.02 \mathrm{~A}$ in phase $\mathrm{D}$, which are all less than $2.5 \%$ of the actual current, confirming a good accuracy over a wide speed range.

It should be noted that the $\mathrm{A} / \mathrm{D}$ converter is triggered in the low level of the injected pulse, which ensures the synchronization between the injected pulses and A/D samplings. Furthermore, because the pulse injection frequency is the same as the traditional phase current sampling frequency, the real-time current can be obtained in the same way as the traditional SRM systems, which will not affect the control accuracy.

Fig. 15 illustrates the dynamic performance of the dual motor drive with two independent closed-loop controllers based on the proposed public-sensor based technique. The proportional and integral (PI) algorithm is employed in the system to regulate the motor speed. Fig. 15(a)-(c) shows the dynamic response to speed variations. In both acceleration conditions, when motor 1 speed rises from 300 to $1500 \mathrm{r} / \mathrm{min}$ and motor 2 speed rises from 400 to $1500 \mathrm{r} / \mathrm{min}$, the speeds of the two motors both follow the given values well despite the speed commands for the two motors are given at different times, as shown in Fig. 15(a). In both deceleration conditions, the speeds of the two motors also faithfully follow the given values, as shown in Fig. 15(b). When motor1 accelerates and motor 2 decelerates, the two speeds are also rapidly stabilized within $1 \mathrm{~s}$, as shown in Fig. 15(c). Fig. 15(d)-(f) show the dynamic response to load variations. Motor1 and motor 2 are operated at 300 and $1500 \mathrm{r} / \mathrm{min}$, respectively. When the loads of motor 1 and motor 2 both increase from 1 to $2 \mathrm{~N} \cdot \mathrm{m}$ and both decrease from 2 to $1 \mathrm{~N} \cdot \mathrm{m}$, the speeds all stabilize within 500 ms, as shown in Fig. 15(d) and (e). When the load of motor1 increases from 1 to $2 \mathrm{~N} \cdot \mathrm{m}$ and the load of motor 2 decreases from 2 to $1 \mathrm{~N} \cdot \mathrm{m}$, the two speeds still can be easily controlled, as shown in Fig. 15(f). The experimental results show an excellent dynamic response both to the speed and load variations. Therefore, the developed dual motor drive system can provide independent current control for the two motors.

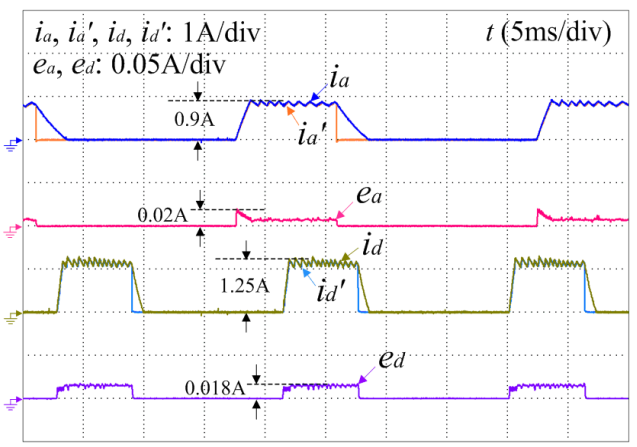

(a)

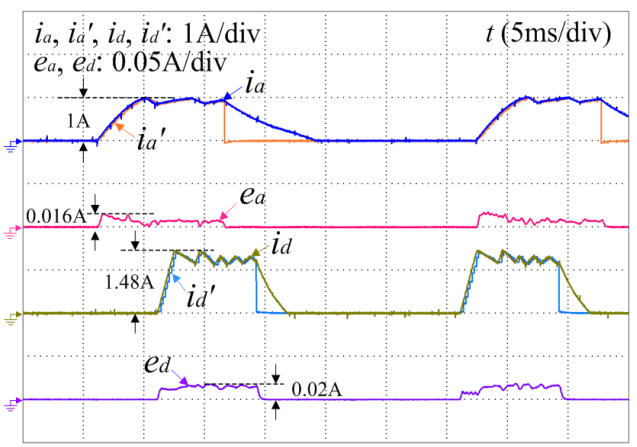

(b)

Fig. 14. Current comparison. (a) $300 \mathrm{r} / \mathrm{min}$ for motor1 and $400 \mathrm{r} / \mathrm{min}$ for motor2. (b) $1200 \mathrm{r} / \mathrm{min}$ for motor 1 and $1500 \mathrm{r} / \mathrm{min}$ for motor 2.

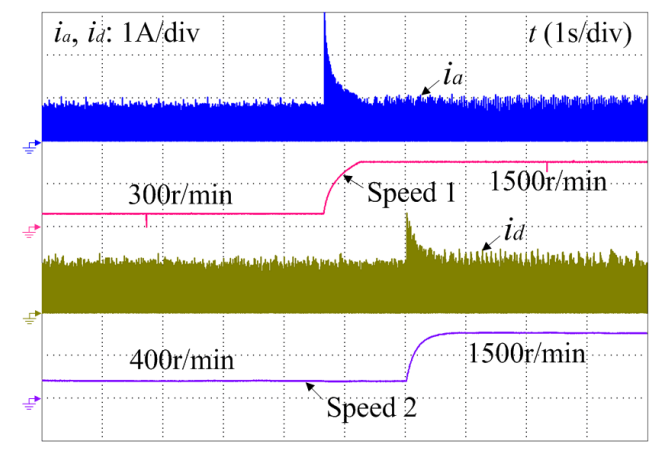

(a) 


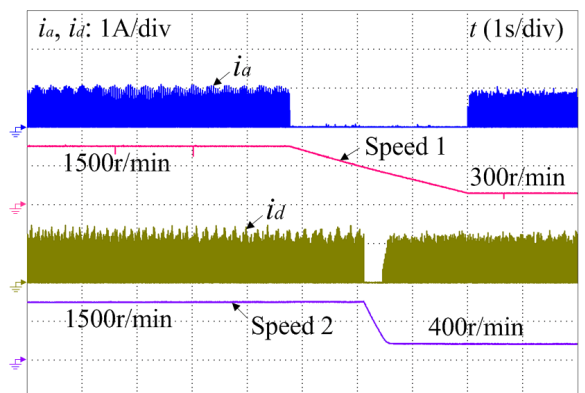

(b)

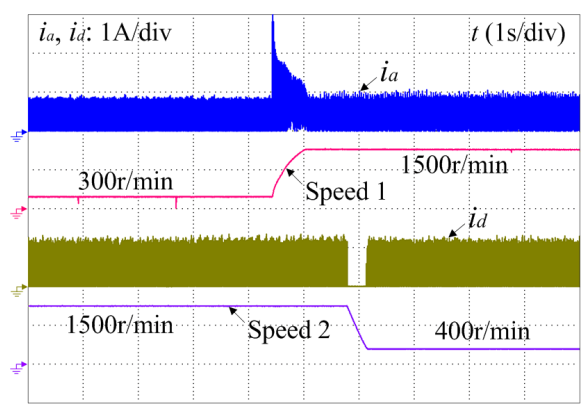

(c)

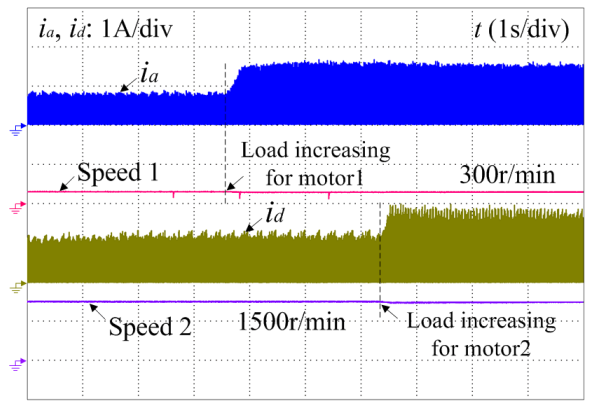

(d)

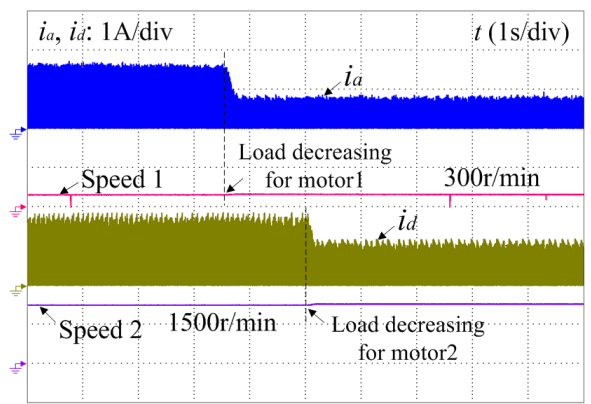

(e)

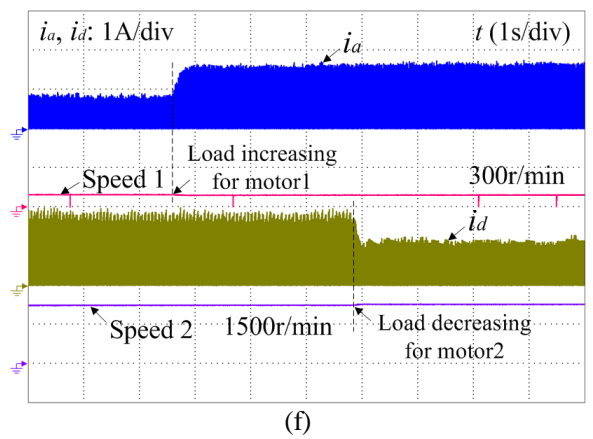

Fig. 15. Dynamic performance of the dual motor drive with independent closed-loop controllers based on public current sensing. (a) Both accelerate. (b) Both decelerate. (c) Motor1 accelerates and motor 2 decelerates. (d) Both load increasing. (e) Both load decreasing. (f) Motor1 load increasing and motor2 load decreasing.
In order to investigate the performance comparison between the traditional method using multiple current sensors and the proposed scheme using a public current sensor in the dual motor drive system, the efficiency, torque ripple are given in Fig. 16. Clearly, the proposed method does not obviously reduce the motor drive efficiency, and give rise to the torque ripple and speed ripple. Therefore, the performances of both motors are not degraded, although the current sensors are reduced.

The frequency of the injected pulse is only $20 \mathrm{kHz}$, and only the lower-transistors are involved in the excitation regions. It is true that the extra switching losses are caused by the pulse injection. However, from the efficiency comparison in Fig. 16(a), it can be seen that the efficiencies are not obviously degraded compared to traditional methods. Therefore, the power losses are not obviously changed due to the limited switching actions.

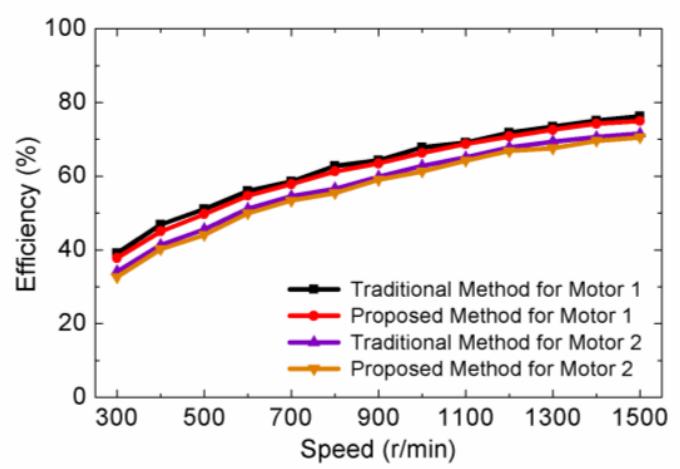

(a)

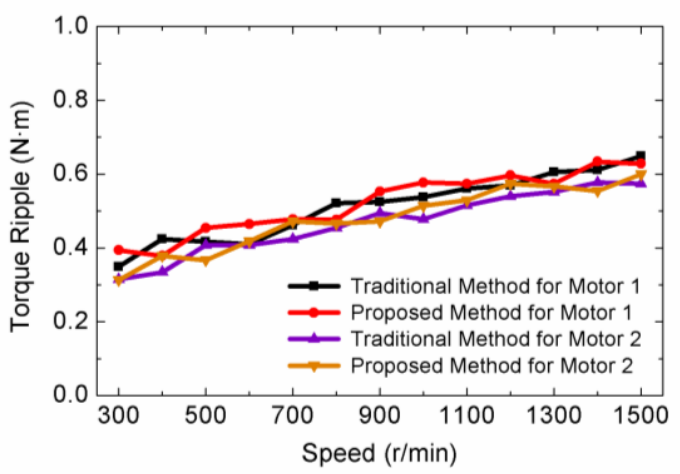

(b)

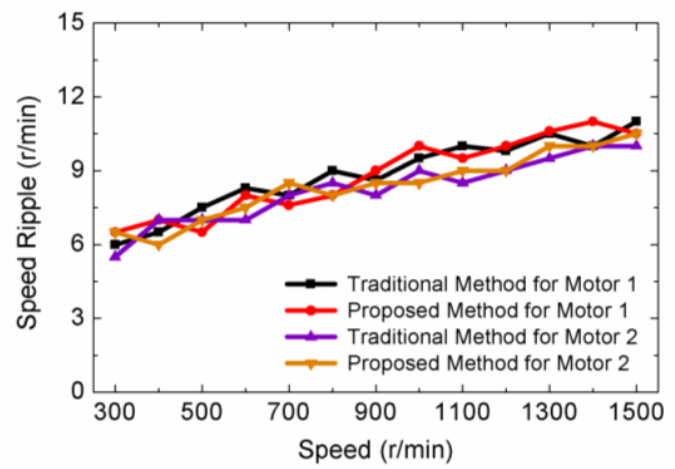

(c)

Fig. 16. Performance comparison. (a) Efficiency. (b) Torque ripple. (c) Speed ripple. 


\section{CONCLUSION}

In this paper, an independent current control technique with low-cost public current sampling for dual SRM drive is proposed so as to achieve a cost-effective dual motor drive. Two three-phase 12/8 SRM drives connected in parallel are extensively tested to validate the proposed technique. In order to identify all the phase currents from the public current for regulation, pulse injection and current sampling methods are presented accordingly. The two motors in the dual drive system can be controlled independently by using the proposed public-sensor based technique, although the motor parameters and control parameters for the two motors are different. The dynamic performance of the dual motor drive with two dependent closed-loop controllers is investigated. The cost and volume of the dual drive system can be reduced by replacing all the phase current sensors with only a public sensor, which will make the product more compact and cost-effective. Therefore, the proposed control technique is very suitable for applications which are sensitive to cost and require high torque capacity, such as low-speed sightseeing vehicles, forklifts, and conveyer belts, etc.

In high performance and safety critical applications, the proposed scheme can also provide a simple and reliable faulttolerance method for current sensor faults. When the dual drive system is in healthy condition, the public current sensor stays in the idle mode; while it is put into use when fault occurs in one current sensor or faults occur in multiple current sensors.

\section{REFERENCES}

[1] J. Yu, W. Pei, and C. Zhang, "A loss-minimization port-controlled hamilton scheme of induction motor for electric vehicles," IEEE/ASME Trans. Mechatronics, vol. 20, no. 6, pp. 2645-2653, Dec. 2015.

[2] E. Silvas, T. Hofman, A. Serebrenik, and M. Steinbuch, "Functional and cost-based automatic generator for hybrid vehicles topologies," IEEE/ASME Trans. Mechatronics, vol. 20, no. 4, pp. 1561-1572, Aug. 2015.

[3] T. D. Do, H. H. Choi, and J. W. Jung, "Nonlinear optimal DTC design and stability analysis for interior permanent magnet synchronous motor drives," IEEE/ASME Trans. Mechatronics, vol. 20, no. 6, pp. 27162725, Dec. 2015.

[4] F. Aghili, "Energy-efficient and fault-Tolerant control of multiphase nonsinusoidal PM synchronous machines," IEEE/ASME Trans. Mechatronics, vol. 20, no. 6, pp. 2736-2751, Dec. 2015.

[5] A. V. Sant, V. Khadkikar, W. Xiao, and H. H. Zeineldin, "Four-axis vector-controlled dual-rotor PMSM for plug-in electric vehicles," IEEE Trans. Ind. Electron., vol. 62, no. 5, pp. 3202-3212, May 2015.

[6] A. Chiba, K. Kiyota, N. Hoshi, M. Takemoto, and S. Ogasawara, "Development of a rare-earth-free SR motor with high torque density for hybrid vehicles," IEEE Trans. Energy Convers., vol. 30, no. 1, pp. 175-182, Mar. 2015.

[7] I. Boldea, L. N. Tutelea, L. Parsa, and D. Dorrell, "Automotive electric propulsion systems with reduced or no permanent magnets: an overview," IEEE Trans. Ind. Electron., vol. 61, no. 10, pp. 5696-5711, Oct. 2014.

[8] B. Bilgin, A. Emadi, and M. Krishnamurthy, "Comprehensive evaluation of the dynamic performance of a 6/10 SRM for traction application in PHEVs," IEEE Trans. Ind. Electron., vol. 60, no. 7, pp. 2564-2575, Jul. 2013.

[9] K. W. Hu, P. H. Yi, and C. M. Liaw, "An EV SRM drive powered by battery/supercapacitor with $\mathrm{G} 2 \mathrm{~V}$ and $\mathrm{V} 2 \mathrm{H} / \mathrm{V} 2 \mathrm{G}$ capabilities," IEEE Trans. Ind. Electron., vol. 62, no. 8, pp. 4714-4727, Aug. 2015.

[10] K. Kiyota, T. Kakishima, and A. Chiba, "Comparison of test result and design stage prediction of switched reluctance motor competitive with
60-kW rare-earth PM motor," IEEE Trans. Ind. Electron., vol. 61, no. 10, pp. 5712-5721, Oct. 2014.

[11] Y. Hu, X. Song, W. Cao, and B. Ji, "New SR drive with integrated charging capacity for plug-in hybrid electric vehicles (PHEVs)," IEEE Trans. Ind. Electron., vol. 61, no. 10, pp. 5722-5731, Oct. 2014.

[12] Y. T. Chang, K. W. E. Cheng, and S. L. Ho, "Type-V exponential regression for online sensorless position estimation of switched reluctance motor," IEEE/ASME Trans. Mechatronics, vol. 20, no. 3, pp. 1351-1359, Jun. 2015.

[13] H. Chen, and J. J. Gu, "Implementation of the three-phase switched reluctance machine system for motors and generators," IEEE/ASME Trans. Mechatronics, vol. 15, no. 3, pp. 421-432, Jun. 2010.

[14] W. Ding, Y. Hu, and L. Wu, "Analysis and development of novel threephase hybrid magnetic paths switched reluctance motors using modular and segmental structures for EV applications," IEEE/ASME Trans. Mechatronics, vol. 20, no. 5, pp. 2437-2451, Oct. 2015.

[15] C. Liu, Z. Deng, L. Xie, and K. Li, "The design of the simple structurespecified controller of magnetic bearings for the high-speed SRM," IEEE/ASME Trans. Mechatronics, vol. 20, no. 4, pp. 1798-1808, Aug. 2015.

[16] J. Cai, and Z. Deng, "Sensorless control of switched reluctance motor based on phase inductance vectors," IEEE Trans. Power Electron., vol. 27, no. 7, pp. 3410-3423, Jul. 2012.

[17] J. Ye, B. Bilgin, and A. Emadi, "An extended-speed low-ripple torque control of switched reluctance motor drives," IEEE Trans. Power Electron., vol. 30, no. 3, pp. 1457-1470, Mar. 2015.

[18] Y. S. Lai, W. T. Lee, Y. K. Lin, and J. F. Tsai, "Integrated inverter/converter circuit and control technique of motor drives with dual-mode control for EV/HEV applications," IEEE Trans. Power Electron., vol. 29, no. 3, pp. 1358-1365, Mar. 2014.

[19] Y. Hu, Z. Q. Zhu, and K. Liu, "Current control for dual three-phase permanent magnet synchronous motors accounting for current unbalance and harmonics," IEEE Journal of Emerging and Selected Topics in Power Electronics, vol. 2, no. 2, pp. 272-284, Jun. 2014.

[20] X. Chen, Z. Deng, J. Peng, and X. Li, "Comparison of two different fault-tolerant switched reluctance machines for fuel pump drive in aircraft," in Proc. IEEE Int. Power Electron. Motion Control Conf., May. 2009, pp. 2086-2090.

[21] E. Levi, M. Jones, S. N. Vukosavic, and H. A. Toliyat, "A novel concept of a multiphase, multimotor vector controlled drive system supplied from a single voltage source inverter," IEEE Trans. Power Electron., vol. 19, no. 2, pp. 320-335, Mar. 2004.

[22] M. Jones, S. N. Vukosavic, and E. Levi, "Parallel-connected multiphase multidrive systems with single inverter supply," IEEE Trans. Ind. Electron., vol. 56, no. 6, pp. 2047-2057, Jun. 2009.

[23] W. Ding, "Comparative study on dual-channel switched reluctance generator performances under single- and dual-channel operation modes," IEEE Trans. Energy Convers., vol. 27, no. 3, pp. 680-688, Sep. 2012.

[24] W. Ding, D. Liang, and H. Sui, "Dynamic modeling and performance prediction for dual-channel switched reluctance machine considering mutual coupling," IEEE Trans. Magn., vol. 46, no. 9, pp. 3652-3663, Sep. 2010.

[25] P. Sun, C. Liu, J. S. Lai, and C. L. Chen, "Cascade dual buck inverter with phase-shift control," IEEE Trans. Power Electron., vol. 27, no. 4, pp. 2067-2077, Apr. 2012.

[26] B. Akin, M. Bhardwaj, and S. Choudhury, "An integrated implementation of two-phase interleaved PFC and dual motor drive using single MCU with CLA," IEEE Trans. Ind. Inf., vol. 9, no. 4, pp. 2082-2091, Nov. 2013.

[27] D. Dujic, M. Jones, S. N. Vukosavic, and E. Levi, "A general PWM method for a $(2 n+1)$-leg inverter supplying $n$ three-phase machines," IEEE Trans. Ind. Electron., vol. 56, no. 10, pp. 4107-4118, Oct. 2009.

[28] C. S. Lim, E. Levi, M. Jones, N. A. Rahim, and W. P. Hew, "A comparative study of synchronous current control schemes based on FCS-MPC and PI-PWM for a two-motor three-phase drive," IEEE Trans. Ind. Electron., vol. 61, no. 8, pp. 3867-3878, Aug. 2014.

[29] S. K. Sahoo, S. K. Panda, and J. X. Xu, "Iterative learning-based highperformance current controller for switched reluctance motors," IEEE Trans. Energy Convers., vol. 19, no. 3, pp. 491-498, Sep. 2004. 
[30] S. E. Schulz, and K. M. Rahman, "High-performance digital PI current regulator for EV switched reluctance motor drives," IEEE Trans. Ind. Appl., vol. 39, no. 4, pp. 1118-1126, Jul./Aug. 2003.

[31] R. B. Inderka, and R. W. A. A. De Doncker, "High-dynamic direct average torque control for switched reluctance drives," IEEE Trans. Ind. Appl., vol. 39, no. 4, pp. 1040-1045, Jul./Aug. 2003.

[32] H. Kim, M. Falahi, T. M. Jahns, and M. W. Degner, "Inductor current measurement and regulation using a single DC link current sensor for interleaved DC-DC converters," IEEE Trans. Power Electron., vol. 26, no. 5, pp. 1503-1510, May 2011.

[33] Y. Cho, A. Koran, H. Miwa, B. York, and J. S. Lai, "An active current reconstruction and balancing strategy with dc-link current sensing for a multi-phase coupled-inductor converter," IEEE Trans. Power Electron., vol. 27, no. 4, pp. 1697-1705, 2012.

[34] Y. S. Lai, Y. K. Lin, and C. W. Chen, "New hybrid pulsewidth modulation technique to reduce current distortion and extend current reconstruction range for a three-Phase inverter using only DC-link sensor," IEEE Trans. Power Electron., vol. 28, no. 3, pp. 1331-1337, Mar. 2013.

[35] H. Shin, and J. I. Ha, "Phase current reconstructions from DC-link currents in three-phase three-level PWM inverters," IEEE Trans. Power Electron., vol. 29, no. 2, pp. 582-593, Feb. 2014.

[36] P. C. Kjaer and G. G. Lopez, "Single-sensor current regulation in switched reluctance motor drives," IEEE Trans. Ind. Appl., vol. 34, no. 3, pp. 444-451. May/Jun. 1998.

[37] H. Lu, X. Cheng, W. Qu, S. Sheng, Y. Li, and Z. Wang, "A three-phase current reconstruction technique using single DC current sensor based on TSPWM," IEEE Trans. Power Electron., vol. 29, no. 3, pp. 15421550, Mar. 2014.

[38] Y. Gu, F. Ni, D. Yang, and H. Liu, "Switching-state phase shift method for three-phase-current reconstruction with a single dc-link current sensor," IEEE Trans. Ind. Electron., vol. 58, no. 11, pp. 5186-5194, Nov. 2011.

[39] C. Gan, J. Wu, S. Yang, and Y. Hu, "Phase current reconstruction of switched reluctance motors from dc-link current under double highfrequency pulses injection," IEEE Trans. Ind. Electron., vol. 62, no. 5, pp. 3265-3276, May 2015.

[40] M. Bertoluzzo, G. Buja, and R. Menis, "Direct torque control of an induction motor using a single current sensor," IEEE Trans. Ind. Electron., vol. 53, no. 3, pp. 778-784, Jun. 2006.

[41] H. Ye, and A. Emadi, "A six-phase current reconstruction scheme for dual traction inverters in hybrid electric vehicles with a single dc-link current sensor," IEEE Trans. Veh. Technol., vol. 63, no. 7, pp. 30853093, Sep. 2014 